\title{
Fimbriae and Haemagglutinating Activity in Strains of Proteus hauseri
}

\author{
BY W. I. H. SHEDDEN \\ Bacteriology Department, Sheffield University
}

(Received 22 March 1961)

\begin{abstract}
SUMMARY
Fimbriae were seen with the electron microscope on each of 79 strains of Proteus hauseri when these were in the haemagglutinating phase, but were absent from the non-haemagglutinating phase. All strains were variably fimbriate. The fimbriate mutant became dominant under anaerobic or relatively anaerobic cultural conditions. The non-fimbriate mutant became dominant under aerobic conditions. The properties of Proteus fimbriae are compared with those of Escherichia coli and Shigella flexneri. The fimbriation change is correlated with other mutations in Proteus strains.
\end{abstract}

\section{INTRODUCTION}

Non-flagellar filamentous appendages were observed with the electron microscope on a variety of organisms by Anderson (1949), Houwink \& van Iterson (1950) and others. In the absence of any name, these appendages were called 'fimbriae' by Duguid, Smith, Dempster \& Edmunds (1955). More recently, Russian workers have referred to them as 'cilia' (Pershina \& Vasil'eva, 1960). Many of the Enterobacteriaceae are fimbriate or become so under appropriate cultural conditions. Fimbriae have been observed in a majority of strains of Escherichia coli (Duguid et al. 1955; Cefalu, 1960), in Aerobacter cloacae (Constable, 1956), Shigella flexneri (Duguid \& Gillies, 1957; Cefalu, 1960), Chromobacterium prodigiosum and Salmonella spp. (Duguid \& Gillies, 1958) and in Klebsiella strains (Duguid, 1959). Some species, for example Aerobacter cloacae, were fimbriate under all cultural conditions; others, for example $S$. flexneri, were variably fimbriate. The variation was dictated by the cultural conditions.

Fimbriate organisms attach themselves to, and cause agglutination of, various animal and plant cells, e.g. erythrocytes, leucocytes, intestinal epithelial cells, Candida albicans cells, etc. In most species, haemagglutination is inhibited by D-mannose or $\alpha$-methylmannoside (Duguid \& Gillies, 1957); in a minority of fimbriate strains, such inhibition was not observed (Duguid, 1959). These latter strains did not adhere to untreated red cells, leucocytes or 'smooth' yeasts. They did adhere to erythrocytes treated with tannic acid, red cell stromata heated at $70^{\circ}$ or $100^{\circ}$, fungus mycelium and plant root hairs.

Fimbriae have been observed in Proteus strains (Duguid \& Gillies, 1958). The object of the present work was to study the fimbriation of strains of Proteus hauseri, and to compare it with those species which have already been investigated. 


\section{METHODS}

The strains used were obtained from the following sources. Stock strains (from Dr R. R. Gillies, Department of Bacteriology, Edinburgh University): reference numbers 1-22. These were originally isolated from pathological material and had been maintained for 5 years on nutrient agar slopes, stored at $4^{\circ}$. Recently isolated strains (from Dr E. H. Gillespie, Public Health Laboratory, City Hospital, Sheffield): reference numbers 23-71. These were isolated from pathological material during the 4-month period in which this survey was carried out; they were maintained as nutrient agar slope cultures stored at $4^{\circ}$. National Collection of Type Cultures (NCTC): 8 strains, reference numbers NCTC 4635, 4636, 3177, 4199, 4175, 401, 60, 2100. Of these strains 8 were 'vulgaris' and 71 'mirabilis' varieties.

Media. Peptone water: Bacto peptone, $1 \mathrm{~g}$., NaCl, $0.5 \mathrm{~g}$., water, $100 \mathrm{ml}$.; $\mathrm{pH} 7 \cdot 0-7 \cdot 1$. Test tubes were filled with $10 \mathrm{ml}$. quantities, plugged with cotton wool and sterilized by autoclaving at $121^{\circ}$ for $15 \mathrm{~min}$. Nutrient agar: Bacto peptone, 1 g.; Lab Lemco., 1 g.; NaCl, 0.5 g.; Japanese agar, 20 g.; water, $100 \mathrm{ml}$.

Haemagglutination tests were made with various animal red cells. Cells from freshly drawn citrated blood were twice washed with saline $(\mathrm{NaCl}, 0 \cdot 85 \%, \mathrm{w} / \mathrm{v})$ and then prepared as a $3 \%(\mathrm{v} / \mathrm{v})$ suspension in saline. The method of testing was a modification of the method described by Duguid (1959). The bacillary deposit from a centrifuged peptone water culture was suspended in $1 \mathrm{ml}$. saline; $0.25 \mathrm{ml}$. of this suspension was added to an equal volume of red cell suspension in a depression in the surface of a white tile (of the kind used for embedding tissue blocks in paraffin wax). This was shaken for $30 \mathrm{~min}$. in a horizontal plane on a Townson and Mercer small shaker, regulated to 50 oscillations $/ \mathrm{min}$. The advantage of using the large volume $(0.5 \mathrm{ml}$.) is that the tests do not tend to dry up during shaking. Also some weak reactions appeared after 20 min. which would have been missed by Duguid's method. The strength of haemagglutination was recorded,,,++++++ , $+++($ Table 1$)$.

Table 1. Correlation between haemagglutinating activity for sheep red cells and percentage of fimbriate organisms seen by electron microscopy in cultures of 79 Proteus hauseri strains grown by a variety of methods

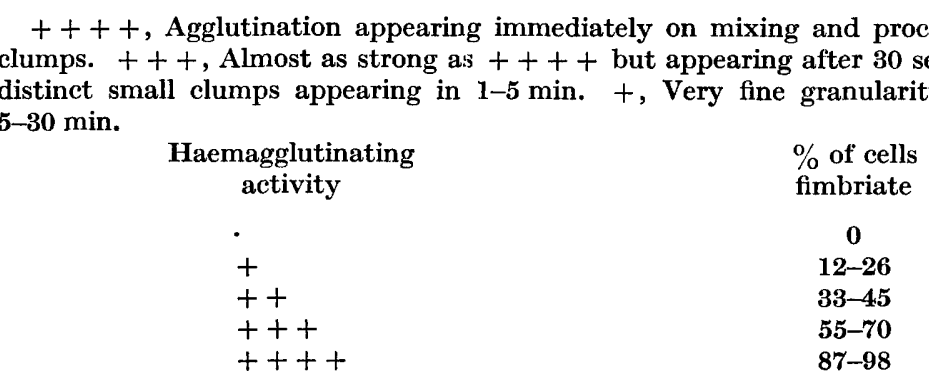

Electron microscopy. The Metropolitan-Vickers E.M. 3 and E.M. 6 instruments were used. Bacterial suspensions were fixed with $\mathbf{0} \cdot \mathbf{2 5} \%$ formaldehyde, washed twice with distilled water and mounted on carbon films. Specimens were shadowed with platinum at $15^{\circ}$. 


\section{RESULTS \\ Haemagglutination by Proteus strains}

The effect of cultural conditions on the development of haemagglutinating activity was investigated. All strains were subcultured serially in static tubes of peptone water incubated aerobically at $37^{\circ}$ and on nutrient agar slopes and plates incubated aerobically and anaerobically at $37^{\circ}$ for $24 \mathrm{hr}$. Growth under anaerobic conditions was poor. Series were initiated from non-haemagglutinating agar slope cultures. Strains 1-22 were subcultured 20 times; the other strains, a minimum of 12 times. The haemagglutinating activity for sheep cells was determined for each subculture. Strains 23-59 were examined with the electron microscope for the presence of fimbriae in every fourth subculture. Strains 1-22 and 60-79 were similarly examined in every tenth subculture. These observations were made for all 79 strains grown by each of the above five methods of culture.

None of the 79 strains examined developed any demonstrable haemagglutinating activity during serial culture on well dried nutrient agar slopes or plates incubated aerobically. All 79 strains developed haemagglutinating activity in tubes of peptone water incubated aerobically and on nutrient agar slopes or plates incubated anaerobically. The haemagglutinating power in the different kinds of positive cultures was not determined; no valid comparisons can therefore be made of their haemagglutinating activity. All 79 strains examined were autoagglutinable when suspended in saline solution $(0 \cdot 1-0 \cdot 85 \%, w / v)$. This phenomenon was observed under all five conditions of culture examined. In any high-power microscope field only about $50 \%$ of the organisms occurred singly. The remainder occurred in floccules of about 5 to 100 organisms each. Since the determination of haemagglutinating power (Duguid et al. 1955) is dependent on the preparation of standardized bacterial suspensions, existing quantitative methods are valueless with regard to Proteus strains. The results of this study are qualitative only.

Most of the stock strains and NCTC strains were non-haemagglutinating on first subculture. The majority became haemagglutinating in 2 to 10 subcultures. One strain required 17 subcultures before becoming positive. With very few exceptions, recently isolated strains were haemagglutinating in the first subculture. Once developed, haemagglutinating activity was maintained in subsequent subcultures under the same cultural conditions. All 79 strains were inoculated on nutrient agar plates using as inoculum $0.1 \mathrm{ml}$. of strongly haemagglutinating broth cultures. These were cultured serially at $37^{\circ}$ for $24 \mathrm{hr}$. With 5 subcultures, all strains became non-haemagglutinating. On subsequent subculture in tubes of nutrient broth incubated aerobically at $37^{\circ}$ for $24 \mathrm{hr}$., haemagglutinating activity again manifested itself. This reversal between haemagglutinating and non-haemagglutinating phases was repeated 5 times with all strains. A fuller investigation of this phenomenon was carried out with strains $1,2,3,27,28,31,73,74$ and 76 (selected at random). It was found that all 9 strains became haemagglutinating on serial subculture in tubes of nutrient broth incubated aerobically at $37^{\circ}$ for $24 \mathrm{hr}$. or on nutrient agar plates or slopes incubated anaerobically at $37^{\circ}$ for $48 \mathrm{hr}$. Once positive, all 9 strains became negative again on serial subculture on nutrient agar slopes or plates incubated aerobically at $37^{\circ}$ for $24 \mathrm{hr}$. Conversion to the new phase required 2-5 subcultures 
under the determining conditions. Reversal between the two phases was demonstrated 30 times with all 9 strains.

\section{Electron microscopy}

In all strains, cultures giving a positive haemagglutination test showed the presence of fimbriate organisms. In all strains in the non-haemagglutinating phase no fimbriate organisms were seen. At least 200 organisms, scattered over 20 grid squares, were carefully examined in each preparation. Special care was paid to the examination of any clumps of organisms present. The number of fimbriate organisms seen was expressed as a percentage of the total number of bacteria examined. It was found that there was a rough correlation between the proportion of fimbriate organisms present and the haemagglutinating activity of the culture from which it was prepared. Proteus fimbriae were morphologically identical with those of Escherichia coli and Shigella flexneri (length $0 \cdot 3-2 \mu$; width 8-10 $\mathrm{m} \mu$ ). They were arranged peritrichously but most organisms had denser aggregations at the poles. The number of appendages per organism was very variable; some had as many as 150-200, others as few as 12. Fimbriae curved down and appeared to become attached to the carbon membrane mount.

All strains were also flagellate, and were motile when stab cultured in semi-solid agar, or examined as hanging-drop preparations after growth for $6 \mathrm{hr}$. in peptone water.

\section{Properties of the fimbrial adhesin of Proteus strains}

Neter (1956) reviewed the literature relating to bacterial haemagglutination and emphasized that the mechanism may vary from genus to genus and even from strain to strain in the same genus. He did not mention haemagglutination by Proteus. In the present work it was found that all the Proteus hauseri strains appeared to have a similar mechanism of haemagglutination. The following experiment showed it to be cell-bound and non-diffusible. Strongly haemagglutinating $96 \mathrm{hr}$. peptone water cultures of all 79 strains were centrifuged at $10,000 \mathrm{~g}$ until the supernatant fluid was clear; $0.5 \mathrm{ml}$. of this was transferred to a sterile Wassermann tube and $0.5 \mathrm{ml}$. of a $1 \%(\mathrm{v} / \mathrm{v})$ suspension of washed sheep erythrocytes was added. No haemagglutination was seen after observation for $4 \mathrm{hr}$. at $4^{\circ}, 22^{\circ}$ or $37^{\circ}$. In common with the fimbrial haemagglutinin of Shigella flexneri (Duguid \& Gillies, 1957) the haemagglutinating activity of the bacterial deposit was substantially unaltered by 10 repetitions of centrifugation at $2500 \mathrm{~g}$ followed by resuspension in saline.

The haemagglutinating activity of Proteus hauseri strains was the same when tested at $40^{\circ}, \mathbf{2 2}^{\circ}, \mathbf{3 7}^{\circ}$ and $55^{\circ}$. In this respect the haemagglutinin resembles that of Shigella flexneri but differs from that of some strains of Escherichia coli (Duguid et al. 1955). These $E$. coli strains gave their strongest reactions at $4^{\circ}$ and elution took place when the temperature was raised (Duguid et. al. 1955). The Proteus haemagglutinin was not affected by heating in saline, acetone or $95 \%(\mathrm{v} / \mathrm{v})$ ethanol in water. Haemagglutinating activity was completely destroyed by boiling at $100^{\circ}$ for $2 \mathrm{~min}$. Similar results have been obtained with $E$. coli and $S$. flexneri strains.

The specificity of haemagglutination by Proteus hauseri strains differs from that of other genera which have been investigated. In a survey of haemagglutinating activity for red cells of nine species (Table 2) the reactions were strongest for sheep 
cells and weakest for human blood. The red cells of other vertebrates were agglutinated with intermediate strength. Most fimbriate strains of Escherichia coli (Duguid et al. 1955) and all fimbriate strains of Shigella flexneri (Duguid \& Gillies, 1957) strains gave their strongest reactions with guinea-pig cells.

Table 2. The haemagglutinating activity of six representative Proteus hauseri strains for a range of nine species of red blood cells

\begin{tabular}{|c|c|c|c|c|c|c|c|c|c|c|}
\hline \multirow[b]{2}{*}{$\begin{array}{l}\text { Proteus } \\
\text { strain }\end{array}$} & \multirow[b]{2}{*}{ Origin } & \multicolumn{9}{|c|}{ Haemagglutinating activity for red cells of } \\
\hline & & Sheep & Fowl & Guinea-pig & Horse & Rabbit & Hamster & Mouse & Ox & $\underset{\text { (group O) }}{\operatorname{Man}}$ \\
\hline 10 & Stock & $++++^{*}$ & ++ & ++ & ++ & $t+t$ & +++ & $++t$ & +++ & ++ \\
\hline 11 & Stock & +++ & ++++ & $+t+$ & ++ & +++ & +++ & $++t$ & ++ & ++ \\
\hline 30 & Recent & $++t+$ & ++++ & +++ & ++++ & +++ & +++ & ++ & +++ & $+t+$ \\
\hline 31 & Recent & ++++ & ++++ & ++++ & +++ & +++ & ++++ & ++++ & +++ & +++ \\
\hline 4635 & NCTC & ++++ & ++++ & +++ & +++ & +++ & ++++ & ++++ & +++ & +++ \\
\hline 4199 & NCTC & ++ & ++ & ++ & + & ++ & + & + & + & . \\
\hline
\end{tabular}

\section{Adhesion tests}

The mechanism of haemagglutination was studied by direct microscopy. Two drops of washed sheep red cells were separately placed on a clean microscope slide. To one drop was added a dense suspension of a fimbriate Proteus hauseri. To the other drop was added a similar volume of a suspension of the homologous organism in the non-fimbriate phase. Individual coverslips were placed on each drop and the two compared by phase contrast microscopy. Fimbriate organisms adhered to red cells with which they made random collisions. Aggregates of red cells were built up. Homologous non-fimbriate organisms did not adhere to red cells and aggregates were not built up. By the same technique, fimbriate $\boldsymbol{P}$. hauseri organisms were observed to adhere to Candida albicans cells and to the surface of glass slides which had been cleaned by immersion in ethanol followed by flaming.

\section{Mannose inhibition tests}

Mannose has been shown to inhibit haemagglutination by Escherichia coli and Shigella flexneri strains (Duguid \& Gillies, 1957). Duguid (1959) in a study of fimbriate Klebsiella strains described MS (Mannose sensitive) and MR (mannose resistant) fimbrial adhesions. Strains having MS activity agglutinated guinea-pig red cells strongly and failed to agglutinate ox red cells. Agglutination was inhibited by mannose at $0.5 \%(\mathrm{w} / \mathrm{v})$. Strains possessing MR activity did not agglutinate guinea-pig red cells. However, they did agglutinate ox red cells which had previously been tanned by Boyden's method (Boyden, 1951). Haemagglutination of tanned ox red cells was not inhibited by mannose. Some strains showed a mixture of MS and MR activity.

All the Proteus hauseri strains used in this work were tested for mannose inhibition of agglutination by the method described by Duguid \& Gillies (1957). No strains showed inhibition or diminution of haemagglutinating activity. The following compounds were also without effect $-\alpha$-methyl mannoside, $\alpha$-methyl glucoside, $\mathrm{D}$-xylose, glycerol, raffinose, mannitol, galactose, lactose, maltose, glucose, arabinose. Serial sub-cultures of strains $23-71$ in peptone water aerobically at $37^{\circ}$ for $24 \mathrm{hr}$. were tested 
against sheep, ox and tanned ox red cells. All strains agglutinated sheep red cells strongly. The haemagglutinating activity for ox and tanned ox red cells was of equal strength, but was not as strong as for sheep red cells. The fimbrial haemagglutinin of $\boldsymbol{P}$. hauseri strains, therefore, though mannose resistant, differs from the MR haemagglutinin Klebsiella strains. It is suggested that it be designated the MRP fimbrial adhesin.

\section{Pellicle formation by Proteus hauseri strains}

Duguid \& Gillies (1957) reported that Shigella flexneri while in the fimbriate phase formed a thin membranous pellicle when incubated aerobically in tubes of nutrient broth; the homologous organism in the non-fimbriate phase did not form a pellicle. Similar observations were made with Proteus hauseri strains. The appearance of a pellicle which was thin and membranous was invariably accompanied by the development of haemagglutinating activity. On further serial culture, most strains also formed a thick waxy pellicle which broke up and sank when the tube was shaken. It could thus be separated from the thin 'fimbriate' pellicle which broke up and clung to the sides of the tube above the surface of the medium. Unlike $S$. flexneri strains, the haemagglutinating activity of $\boldsymbol{P}$. hauseri strains did not diminish when the pellicle became thick. No strain developed a waxy pellicle before developing a 'fimbriate' pellicle.

\section{Fimbriation and phase variation}

Belyavin (1951) described three phases in Proteus vulgaris strains. These were identified by their colonial appearance on MacConkey's agar, modified by the addition of $0.5 \%(\mathrm{w} / \mathrm{v}) \mathrm{NaCl}$, and by the way in which they spread on nutrient agar plates incubated aerobically at $37^{\circ}$. By Belyavin's criteria, $A, B$ and $C$ phase colonies were identified and picked from MacConkey plate cultures of $\boldsymbol{P}$. hauseri strains, 12, 14 and 60. These were inoculated on to nutrient agar plates. Inoculation was in the form of a single streak in the middle of the surface of the plate. After aerobic incubation for $24 \mathrm{hr}$. at $37^{\circ} A$ phase cultures swarmed in a series of concentric rings, $C$ phase cultures as a flat sheet and $B$ phase did not spread. From these cultures individual tubes of peptone water were inoculated. These were subcultured serially at $37^{\circ}$ for $24 \mathrm{hr}$. under aerobic conditions. The phase of each serial culture was determined by plating on nutrient agar and observing the mode of spread. The haemagglutinating activity of each serial peptone water culture was also determined. All series which had been initiated from $A$ and $C$ phase cultures became haemagglutinating in the second subculture, and maintained stable haemagglutinating activity in 5 subsequent subcultures. Neither the $\boldsymbol{A}$ nor the $C$ phase was stable, and both rapidly (3rd subculture) assumed a mode of spread which was intermediate between the sharp etched rings characteristic of the $A$ phase, and the flat sheet of the $C$ phase. Series initiated from $B$ phase cultures did not become haemagglutinating even after 15 serial cultures. The $B$ phase remained stable throughout the series.

\section{DISCUSSION}

The 79 Proteus hauseri strains examined in this work were variably fimbriate. In this respect they behaved like certain Shigella flexneri (Duguid \& Gillies, 1957) and Escherichia coli strains (Duguid et el. 1955). Fimbriate organisms were seen in 
large proportions after serial subculture in conditions in which the oxygen tension was low. Fimbriate organisms were not seen after serial subculture in conditions of high oxygen tension. Variation between fimbriate and non-fimbriate phases was shown to take place by serial subculture under the appropriate cultural conditions. As with $\boldsymbol{S}$. flexneri and the variable $\boldsymbol{E}$. coli strains, this change required several serial subcultures under the determining cultural conditions. This is in keeping with the hypothesis that the phenomenon is due to the selection of spontaneously occurring mutants which, for some reason, have a higher survival value.

In common with all other fimbriate species which have been described, Proteus hauseri strains were haemagglutinating, this being strongest for sheep red cells. This at once distinguished Proteus from Escherichia coli, Shigella flexneri, Aerobacter cloacae and Klebsiella aerogenes which gave their strongest reactions with guinea-pig red cells. Haemagglutinating activity by Proteus strains did not vary with the temperature at which the test was carried out. In this respect $\boldsymbol{P}$. hauseri strains resembled $S$. flexneri strains but differed from some $E$. coli strains. Most interesting of all, the haemagglutinating activity of $\boldsymbol{P}$. hauseri strains was not inhibited by mannose. Thus the haemagglutinin did not correspond with either the MS or MR haemagglutinins described by Duguid (1959) in relation to Klebsiella strains. The designation MRP haemagglutinin has been suggested to describe the type of activity exhibited by $P$. hauseri strains.

I should like to thank Professor C. P. Beattie, Dr J. P. Duguid and Dr R. R. Gillies for their interest and advice, Professor R. W. K. Honeycombe for permission to use the electron microscope and Miss Doreen Coles, Mr E. Wade and Mr G. Wilson for technical assistance.

\section{REFERENCES}

Anderson, T. F. (1949). On the mechanism of adsorption of bacteriophages on host cells. Symp. Soc. gen. Microbiol. 1, 76.

Belyavin, G. (1951). Cultural and serological phases of Proteus vulgaris. J. gen. Microbiol. $5,197$.

Boyden, S. V. (1951). The adsorption of proteins on erythrocytes treated with tannic acid. J. exp. Med. 93, 107.

Cefalu, M. (1960). Le fimbrie in Shigella flexneri ed Escherichia coli con particolare riguardo alle proprietà antigeniche. Riv. Ist. Sieroter. ital. 35, 13.

Constable, F. L. (1956). Fimbriae and haemagglutinating activity in strains of Bacterium cloacae. J. Path. Bact. 72, 133.

Duguid, J. P., Smith, I. W., Dempster, G. \& Edmunds, P. N. (1955). Non-flagellar filamentous appendages ('fimbriae') and haemagglutinating activity in Bacterium coli. J. Path. Bact. 70, 335.

Duguid, J. P. \& Gillies, R. R. (1957). Fimbriae and adhesive properties in dysentery bacilli. J. Path. Bact. 74, 397.

Duguid, J. P. \& Gillies, R. R. (1958). Fimbriae and haemagglutinating activity in Salmonella, Klebsiella, Proteus and Chromobacterium. J. Path. Bact. 75, 519.

Duguid, J. P. (1959). Fimbriae and adhesive properties in Klebsiella strains. J. gen. Microbiol. 21, 271.

Houwink, A. L. \& van Iterson, W. (1950). Electron microscopical observations on bacterial cytology. II. A study on flagellation. Biochim. biophys. Acta, 5, 10.

Neter, E. (1956). Bacterial haemagglutination and haemolysis. Bact. Rev. 20, 166.

Pershina, Z. G. \& Vasilyeva, I. G. (1960). Study of the morphology of dysentery bacilli under the electron microscope (cilia of microbial cells). $\mathrm{Zh}$. microbiol. epidemiol. immunobiol. 31, 14. 